Research Article

\title{
Power Battery Recycling Mode Selection Using an Extended MULTIMOORA Method
}

\author{
Xuefeng Ding and Junhui Zhong \\ School of Management, Shanghai University, Shanghai 200444, China \\ Correspondence should be addressed to Junhui Zhong; zjhbetter@163.com
}

Received 10 May 2018; Accepted 25 June 2018; Published 8 July 2018

Academic Editor: Mario Alviano

Copyright (C) 2018 Xuefeng Ding and Junhui Zhong. This is an open access article distributed under the Creative Commons Attribution License, which permits unrestricted use, distribution, and reproduction in any medium, provided the original work is properly cited.

\begin{abstract}
In order to improve the efficiency of the recycling of the electric vehicle power batteries and reduce the recycling cost, it is of great importance to select an optimal power battery recycling mode. In this paper, an extended MULTIMOORA (Multiobjective Optimization by Ratio Analysis plus full Multiplicative form) approach which combines with the two-dimension uncertain linguistic variables (TDULVs) and the regret theory, called TDUL-RT-MULTIMOORA method, is developed for solving the power battery recycling mode decision-making (PBRMDM) problem. Firstly, the evaluations of the power battery recycling modes over criteria are given by the experts using the TDULVs, and the evaluations of all experts are aggregated into a group linguistic decision matrix by the TDULDWA operator. On the basis of the regret theory, the perceived utility decision matrix is constructed. And then, in order to avoid the disadvantages of the subjective weighting methods, such as the deviation from the measured data and the dependence on the experience and knowledge of the experts, an objective entropy weighting method is applied. After that, the MULTIMOORA method is introduced to rank the power battery recycling modes. In the end, an illustrative example is given to verify the effectiveness and practicability of the proposed method.
\end{abstract}

\section{Introduction}

Compared with the traditional fuel vehicles, the electric vehicles have the characteristics of lower emission, lower noise, and lower pollution. In addition, due to the fact that the energy structure required by electric vehicles can be diversified, it helps to get rid of the dependence on nonrenewable oil resources. Therefore, it has a very important practical significance to develop the electric vehicle industry. Nowadays, in China, the electric vehicle industry has been strongly supported by the government and has played an important role in the reduction of greenhouse gas [1]. However, as the energy source of the whole electric vehicle, the life length of the power battery is limited. By 2020, the accumulative number of the power batteries going to enter the end-of-life period in China will reach 120000-170000 tons. If the wasted power batteries are not properly recovered or reused, this will not only cause the wastes of resources but also cause serious pollution to the environment [2]. Therefore, based on the theory of the sustainable development, the reasonable recycling of power batteries is one of the important factors to promote the development of electric vehicle industry.

Issues related to the development of electric vehicles have been widely studied in China recently [3]. Nowadays, there are several recycling modes of power batteries for the electric vehicle manufacturers to adopt. The best selection of the recycling mode will help the manufacturers improve the efficiency of the recovery and reduce the cost. However, in the process of the power battery recycling, because of the complexity and uncertainty of objective things and the fuzziness of human being's thinking, it is difficult to describe the vague information by precise values. The multiple criteria decision-making (MCDM) problem proposed by Churchman et al. [4] is a discipline for supporting experts to figure out an optimal choice from all options based on multiple criteria [5]. Since the power battery recycling mode decisionmaking (PBRMDM) problem involves many qualitative and quantitative evaluation criteria, therefore, it is a feasible way to solve the PBRMDM problem as a MCDM problem. At present, there are few studies on the PBRMDM problem, and 
most of the related researches about the selection of the power battery recycling mode are mainly under the consideration of the recycling cost control. For example, Yun et al. [6] summarized two main basic aspects of recycling batteries, including mechanical procedure and chemical recycling, and proposed a framework for recycling batteries. Ordonez et al. [2] presented a qualitative analyzing approach for solving the recovery and regeneration technology of lithium batteries, which can recycle the valuable elements in the battery. Liu and Gao [7] put forward some corresponding battery recycling countermeasures based on the analysis of the urgency of power battery recycling in China. Tang et al. [8] proposed a rewardpenalty mechanism including some policies for recycling the power battery and the costs of three single recovery modes and three competitive dual recovery modes were also tested by using the Stackelberg game theory.

In the real process of decision-making, it is hard for the decision makers to give their evaluations to the fuzzy or uncertainty information by exact numeric values. Recently, most researchers prefer to represent their opinions by means of the uncertain linguistic information. The uncertain linguistic variables (ULVs) presented by $\mathrm{Xu}$ [9] can express the evaluations of decision makers more accurately. An uncertain linguistic variable (ULV) is composed of a lower limited value and an upper limited value [9]. It can be used in more fuzzy and uncertain situation [10]. However, the ULVs do not consider the reliability of the experts' subject evaluations. Liu and Zhang [11] developed the two-dimension uncertain linguistic variables (TDULVs) to represent the fuzziness of the information on the basis of the ULVs. A two-dimension uncertain linguistic variable (TDULV) is composed of two parts, which includes the I class and the II class linguistic information, where the I class information represents the assessment of decision maker to the evaluated objects, and the II class linguistic information denotes the reliability of the I class assessment denoted by the decision maker. Until now, the TDULVs have been applied in many areas, such as the technology innovation ability evaluation problem [12], the extraefficient economic industry system selection [13], and the river basin ecosystem health evaluation problem [14].

The regret theory was firstly introduced by Loomes and Sugden [15] with the intention of depicting intuitive judgments simply and consistently. It is an important behavioural decision-making theory by considering the outcomes of the alternative choices and the possible results of unselected alternatives. In the regret theory, the perceived utility values are used to measure the expected value of satisfaction by choosing one alternative and rejecting another. Recently, the regret theory has been applied to solve different kinds of problems, such as the selection of the human-agent collaborative teams [16], trip distribution and traffic assignment [17], environmentally friendly supplier selection [18], and the selection of charging facility design for electric vehicles [19].

Entropy weighting method was originally proposed by Shannon [20]. The entropy can measure the probability of objective, and it can show the direct reflection of the information size and its uncertainty [21], and it is also a method with precise calculation process. Due to the characteristic of entropy weighting method, it has been widely applied in many different fields. For example, Liu and Li [22] proposed the comprehensive forecasting model by using the entropy weighting method. Delgado and Reyes [23] used the entropy weighting method to select the best alternative plants. Zhang et al. [24] proposed a novel ship detection method by using the entropy weighting method to extract the features of the synthetic aperture radar images.

Brauers and Zavadskas [25] proposed a MOORA method in 2006. In 2011, Chakrabory checked the robustness of six common MCDM methods, including the MOORA method [25], the AHP method [26], the TOPSIS method [27], the VIKOR method [28], the ELECTRE method [29], and the PROMETHEE method [30], as nonsubjectively as possible, and the results showed that only MOORA method satisfied all conditions of robustness of the MCDM [31]. Inspired by the MOORA method, Brauers and Zavadskas [32] developed a MULTIMOORA method by improving and synthesizing the MOORA method, and the results of the MULTIMOORA method show more robustness and accuracy compared with the MOORA method. The decision process of the MULTIMOORA method includes three parts: the ratio system, the reference point method, and the full multiplicative form of multiple objectives. Until recently, no other method is known as meeting all conditions of robustness for the multiple objects optimization; therefore, the MULTIMOORA method is regarded as the most robust technique for solving the MCDM problem [33]. So far, the MULTIMOORA method has been applied in many areas, such as the materials selection of power gears [34], the biomaterials selection [35], the pharmacological therapy selection [36], the selection of sites for ammunition depots [37], the supplier selection [38], and the risk evaluation problem [39].

Based on the above discussions, in this paper, to solve the PBRMDM problem, an extended MULTIMOORA method with two-dimension uncertain linguistic variables and the regret theory, called the TDUL-RT-MULTIMOORA method, is developed. The remainder of this paper is organized as follows: the preliminaries of this work are introduced in Section 2. Section 3 presents the framework of the TDULRT-MULTIMOORA method. An illustrative instance is conducted to demonstrate the effectiveness and practicality of the proposed method in Section 4. In the end, some conclusions are drawn in Section 5.

\section{Preliminaries}

2.1. Linguistic Variables. Suppose $S=\left\{s_{i} \mid i=0,1, \ldots, g-\right.$ $1\}$ is a predefined linguistic term set with finite and totally ordered elements, where $g$ is an odd number, and then $s_{i} \epsilon$ $S(i=0,1, \ldots, g-1)$ is called a linguistic variable [40].

\subsection{Uncertain Linguistic Variables}

Definition 1 (see [9]). Let $\bar{S}$ be a continuous linguistic term set, $\bar{s} \in \bar{S}$ and $\bar{s}=\left[s_{a}, s_{b}\right]$, where $s_{a}, s_{b} \in \bar{s}(a \leq b)$ are the lower and upper limit value of $\bar{s}$, respectively, and then $\bar{s}$ is called an uncertain linguistic variable (ULV) of $\bar{S}$. 


\subsection{Two-Dimension Uncertain Linguistic Variables}

Definition 2 (see $[11,41])$. Let $\widehat{s}=\left(\left[\dot{s}_{a}, \dot{s}_{b}\right]\left[\ddot{s}_{c}, \ddot{s}_{d}\right]\right)$ be a TDULV, where $\left[\dot{s}_{a}, \dot{s}_{b}\right]$ is the first class of $\widehat{s}$, which expresses the assessment of the decision maker to an evaluated object, while $\left[\ddot{s}_{c}, \ddot{s}_{d}\right]$ is the second class of $\widehat{s}$, which denotes the decision maker's subjective evaluation on the reliability of the first class result. $\dot{s}_{a}, \dot{s}_{b}(a \leq b)$ are the lower and upper limit value of the first class, and $\ddot{s}_{c}, \ddot{s}_{d}(c \leq d)$ are the lower and upper limit value of the second class, respectively, and then $\widehat{s}$ is called a two-dimension uncertain linguistic variable (TDULV).

Definition 3 (see $[42,43])$. Suppose $\widehat{s}_{1}=\left(\left[\dot{s}_{a_{1}}, \dot{s}_{b_{1}}\right],\left[\ddot{s}_{c_{1}}, \ddot{s}_{d_{1}}\right]\right)$ and $\widehat{s}_{2}=\left(\left[\dot{s}_{a_{2}}, \dot{s}_{b_{2}}\right],\left[\ddot{s}_{c_{2}}, \ddot{s}_{d_{2}}\right]\right)$ are any two TDULVs, and then the operational rules between $\widehat{s}_{1}$ and $\widehat{s}_{2}$ are given as below:

(1) $\widehat{s}_{1} \oplus \widehat{s}_{2}=\left(\left[\dot{s}_{a_{1}}, \dot{s}_{b_{1}}\right],\left[\ddot{s}_{c_{1}}, \ddot{s}_{d_{1}}\right]\right)$

$$
\begin{aligned}
& \oplus\left(\left[\dot{s}_{a_{2}}, \dot{s}_{b_{2}}\right],\left[\ddot{s}_{c_{2}}, \ddot{s}_{d_{2}}\right]\right) \\
= & \left(\left[\dot{s}_{a_{1}+a_{2}}, \dot{s}_{b_{1}+b_{2}}\right],\left[\ddot{s}_{\min \left(c_{1}, c_{2}\right)}, \ddot{s}_{\min \left(d_{1}, d_{2}\right)}\right]\right),
\end{aligned}
$$

(2) $\widehat{s}_{1} \otimes \widehat{s}_{2}=\left(\left[\dot{s}_{a_{1}}, \dot{s}_{b_{1}}\right],\left[\ddot{s}_{c_{1}}, \ddot{s}_{d_{1}}\right]\right)$

$$
\begin{aligned}
& \otimes\left(\left[\dot{s}_{a_{2}}, \dot{s}_{b_{2}}\right],\left[\ddot{s}_{c_{2}}, \ddot{s}_{d_{2}}\right]\right) \\
= & \left(\left[\dot{s}_{a_{1}+a_{2}}, \dot{s}_{b_{1}+b_{2}}\right],\left[\ddot{s}_{\min \left(c_{1}, c_{2}\right)}, \ddot{s}_{\min \left(d_{1}, d_{2}\right)}\right]\right),
\end{aligned}
$$

(3) $\frac{\widehat{s}_{1}}{\widehat{s}_{2}}=\frac{\left(\left[\dot{s}_{a_{1}}, \dot{s}_{b_{1}}\right],\left[\ddot{s}_{c_{1}}, \ddot{s}_{d_{1}}\right]\right)}{\left(\left[\dot{s}_{a_{2}}, \dot{s}_{b_{2}}\right],\left[\ddot{s}_{c_{2}}, \ddot{s}_{d_{2}}\right]\right)}$

$$
=\left(\left[\dot{s}_{a_{1} / a_{2}}, \dot{s}_{b_{1} / b_{2}}\right],\left[\ddot{s}_{\min \left(c_{1}, c_{2}\right)}, \ddot{s}_{\min \left(d_{1}, d_{2}\right)}\right]\right) \text {, }
$$$$
a_{2}, b_{2} \neq 0 \text {, }
$$

(4) $\lambda \widehat{s}_{1}=\lambda\left(\left[\dot{s}_{a_{1}}, \dot{s}_{b_{1}}\right],\left[\ddot{s}_{c_{1}}, \ddot{s}_{d_{1}}\right]\right)$

$$
=\left(\left[\dot{s}_{\lambda \times a_{1}}, \dot{s}_{\lambda \times b_{1}}\right],\left[\ddot{s}_{c_{1}}, \ddot{s}_{d_{1}}\right]\right), \quad \lambda \geq 0,
$$

(5) $\left(\widehat{s}_{1}\right)^{\lambda}=\left(\left[\dot{s}_{a_{1}}, \dot{s}_{b_{1}}\right],\left[\ddot{s}_{c_{1}}, \ddot{s}_{d_{1}}\right]\right)^{\lambda}$

$$
=\left(\left[\dot{s}_{\left(a_{1}\right)^{\lambda}}, \dot{s}_{\left(b_{1}\right)^{\lambda}}\right],\left[\ddot{s}_{c_{1}}, \ddot{s}_{d_{1}}\right]\right), \quad \lambda \geq 0 .
$$

Definition 4 (see [10]). Suppose $\widehat{s}=\left(\left[\dot{s}_{a}, \dot{s}_{b}\right],\left[\ddot{s}_{c}, \ddot{s}_{d}\right]\right)$ is a TDULV, and then the expectation value $E(\widehat{s})$ of $\widehat{s}$ is

$$
E(\widehat{s})=\frac{a+b}{2 \times(g-1)} \times \frac{c+d}{2 \times(h-1)} .
$$

Definition 5 (see [10]). Suppose $\widehat{s}_{1}=\left(\left[\dot{s}_{a_{1}}, \dot{s}_{b_{2}}\right],\left[\ddot{s}_{c_{1}}, \ddot{s}_{d_{1}}\right]\right)$ and $\widehat{s}_{2}=\left(\left[\dot{s}_{a_{2}}, \dot{s}_{b_{2}}\right],\left[\ddot{s}_{c_{2}}, \ddot{s}_{d_{2}}\right]\right)$ are any two TDULVs, and if $E\left(\widehat{s}_{1}\right) \geq$ $E\left(\widehat{s}_{2}\right)$, then $\widehat{s}_{1} \geq \widehat{s}_{2}$, or vice versa.

\subsection{Aggregation Operators of the TDULVs}

Definition 6 (see [44]). Let $\widehat{s}_{j}=\left(\left[\dot{s}_{a_{j}}, \dot{s}_{b_{j}}\right]\left[\ddot{s}_{c_{j}}, \ddot{s}_{d_{j}}\right]\right)(j=$ $1,2, \ldots n)$ be a collection of 2DULVs and $w=\left(w_{1}, w_{2}, \ldots, w_{n}\right)$ is the weights associated with $\widehat{s}_{j}$ and $\sum_{j=1}^{n} \omega_{j}=1$. Let $\Omega$ be a set of 2DULVs, then, the WAA: $\Omega^{n} \longrightarrow \Omega$, and if

$$
W A A\left(a_{1}, a_{2}, \ldots, a_{n}\right)=\sum_{i=1}^{n} w_{i} a_{i},
$$

then, the WAA operator is called a weighted arithmetic averaging operator.

Definition 7 (see $[45,46])$. Let $\widehat{s}_{j}=\left(\left[\dot{s}_{a_{j}}, \dot{s}_{b_{j}}\right],\left[\ddot{s}_{c_{j}}, \ddot{s}_{d_{j}}\right]\right)(j=$ $1,2, \ldots, n)$ be a TDULV, $\widehat{S}_{i}=\left\{\widehat{s}_{j}^{(i)} \mid i=1,2, \ldots, m ; j=\right.$ $1,2, \ldots, n\}$ be a clustering class of the TDULVs, $\Omega$ be the set of all TDULVs, and TDULDWA be $\Omega^{n} \longrightarrow \Omega$, if

$$
\begin{aligned}
& \operatorname{TDULDWA}\left(\widehat{s}_{1}, \widehat{s}_{2}, \ldots, \widehat{s}_{n}\right)=\sum_{i=1}^{m} \xi_{i} W A A\left(\widehat{S}_{i}\right) \\
& =\sum_{i=1}^{m} \xi_{i}\left(\sum_{j=1}^{k_{i}} w_{j}^{(i)} \widehat{s}_{j}^{(i)}\right) \\
& =\left(\left[\dot{s}_{\sum_{i=1}^{m} \xi_{i} \sum_{j=1}^{k_{i}} w_{j}^{(i)} a_{j}^{(i)}}, \dot{s}_{\sum_{i=1}^{m} \xi_{i} \sum_{j=1}^{k_{i}} w_{j}^{(i)} b_{j}^{(i)}}\right],\right. \\
& \left.\left[\ddot{s}_{\min c_{j}}, \ddot{s}_{\min d_{j}}\right]\right) \text {, }
\end{aligned}
$$

where

$$
\xi_{i}=\frac{\beta_{i}\left(k_{i} / n\right)}{\sum_{i=1}^{m} \beta_{i}\left(k_{i} / n\right)},
$$

where $\xi_{i}(i=1,2, \ldots m)$ is the weights of $\widehat{s}^{(i)}$, satisfying $\xi_{i} \in$ $(0,1)$ and $\sum_{i=1}^{m} \xi_{i}=1 . \beta_{i} \geq 0$ is the density influence index, and $\beta_{i}=\left(k_{i} / n\right)^{\theta}$; generally, $\theta \in[-10,10] ; k_{i}$ is the number of the elements in $\widehat{S}_{i}(i=1,2, \ldots, m)$, and $\sum_{i=1}^{m} k_{i}=n$; $k_{i} / n$ represents the scale information of the ith cluster group $\widehat{S}_{i} ; \omega^{(i)}=\left(\omega_{1}^{(i)}, \omega_{2}^{(i)}, \ldots, \omega_{k_{i}}^{(i)}\right)^{T}$ is the weight vector of $\widehat{S}_{i}=$ $\left(\widehat{s}_{1}^{(i)}, \widehat{s}_{2}^{(i)}, \ldots, \widehat{s}_{k_{i}}^{(i)}\right)$. Then, the TDULDWA operator is called a two-dimension uncertain linguistic density weighted averaging operator.

2.5. Regret Theory. Loomes and Sugden [15] raised the regret theory for the first time. In the regret theory, the perceived utility function is constructed by accumulating the realized utility of the selected alternative and the regret or rejoice utility between the best alternative and the selected one [15]. The perceived utility function $u_{i}$ of the regret theory is composed of two parts: the utility function $v\left(x_{i}\right)$ and the regret or rejoice function $R\left(v\left(x_{i}\right)-v\left(x^{*}\right)\right)$. Let $A=$ $\left\{A_{1}, A_{2}, \ldots, A_{m}\right\}$ be a set of alternatives and $X=\left\{x_{i} \mid\right.$ $i=1,2, \ldots, m\}$ be the results of all alternatives, where $x_{i}$ is the final evaluation value of the alternative $A_{i}$. Then, $u_{i}$ is constructed as follows [47-49]:

$$
u_{i}=v\left(x_{i}\right)+R\left(v\left(x_{i}\right)-v\left(x^{*}\right)\right),
$$


where

$$
\begin{aligned}
v\left(x^{*}\right) & =\max \left\{v\left(x_{i}\right) \mid i=1,2, \ldots, m\right\}, \\
v\left(x_{i}\right) & =\left(x_{i}\right)^{\alpha}, \\
R\left(v\left(x_{i}\right)-v\left(x^{*}\right)\right) & =1-\exp \left(-\delta\left(v\left(x_{i}\right)-v\left(x^{*}\right)\right)\right),
\end{aligned}
$$

where $R\left(v\left(x_{i}\right)-v\left(x^{*}\right)\right) \leq 0$, which indicates that the expert feels regret after choosing the alternative $A_{i}$ rather than the alternative $A^{*} ; \alpha(0<\alpha<1)$ is the risk aversion coefficient, and the smaller value of $\alpha$, the greater risk aversion of the expert, or vice versa [50]; $\delta(\delta>0)$ is the regret aversion coefficient; the larger value of $\delta$, the greater regret aversion tendency of the expert [51]. Tversky and Kahneman [50] gave the value of $\alpha$ which is equal to 0.88 and $\delta$ equals 0.3 after experimental verification.

2.6. The MULTIMOORA Method. The MULTIMOORA method was first developed by Brauers and Zavadskas [32] on the basis of the MOORA method. It is a powerful tool for dealing with the MCDM problem. The process of MULTIMOORA method is made up of three parts: the ratio system, the reference point method, and the full multiplicative form of multiple objectives. The MULTIMOORA method is the most robust system of multiple objectives optimization than other multiple criteria decision-making methods [33]. Suppose $X=\left[x_{i j}\right](i=1,2, \ldots m, j=$ $1,2, \ldots, n)$ is a decision matrix

$$
X=\left[\begin{array}{cccc}
x_{11} & x_{12} & \cdots & x_{1 n} \\
x_{21} & x_{22} & \cdots & x_{2 n} \\
\vdots & \vdots & \cdots & \vdots \\
x_{m 1} & x_{m 2} & \cdots & x_{m n}
\end{array}\right]_{m \times n},
$$

where $x_{i j}$ is the evaluation value of alternative $A_{i}$ which refers to criteria $C_{j}, i=1,2, \ldots m, j=1,2, \ldots, n$. Then, the steps of MULTIMOORA method are as below.

Step 1 (calculate the importance coefficients of criteria). The importance coefficients of criteria $w_{j r}$ for criteria $C_{j}$ with reference to the criteria $C_{r}$ are calculated by

$$
w_{j r}=\frac{w_{j}}{w_{r}},
$$

where $w_{j}(\mathrm{j}=1,2, \ldots, \mathrm{n})$ is the weight of criterion $C_{j}$, satisfying $w_{j} \in(0,1)$ and $\sum_{j=1}^{n} w_{j}=1$;

$$
w_{r}=\max \left\{w_{j} \mid j=1,2, \ldots, n\right\} .
$$

Step 2 (normalize the decision matrix $X$ into $X^{*}$ ). The decision matrix $X$ is normalized into $X^{*}$ by

$$
X^{*}=\left[\frac{x_{i j}^{*}}{\sqrt{\sum_{i=1}^{m}\left(x_{i j}^{*}\right)^{2}}}\right]_{m \times n} .
$$

Step 3 (the ratio system). In order to obtain the optimization, based on the ratio system, the best alternative is obtained by

$$
A_{R S}^{*}=\left\{A_{i} \mid \max _{i} y_{i}^{*}\right\},
$$

where the overall evaluation value $y_{i}^{*}$ of alternative $A_{i}$ refers to all criteria and is added in the circumstances of maximization and subtracted in the circumstances of minimization for every alternative [52]:

$$
y_{i}^{*}=\sum_{j=1}^{g} \omega_{j} x_{i j}^{*}-\sum_{j=g+1}^{n} \omega_{j} x_{i j}^{*},
$$

where $j=1,2, \ldots, g$ are the benefit criteria; $j=g+1, g+$ $2, \ldots, n$ are the cost criteria.

Step 4 (the reference point approach). The best alternative is got by

$$
A_{R P}^{*}=\left\{A_{i} \mid \min _{i} z_{i}^{*}\right\} .
$$

Then the absolute value $x_{i j}^{*}$ between the reference point $r_{j}$ and the normalized evaluation value of alternative $A_{i}$ refers to criteria $C_{j}$ calculated by

$$
z_{i}^{*}=\max _{j}\left|w_{j} r_{j}-w_{j} x_{i j}^{*}\right|,
$$

where

$$
r_{j}= \begin{cases}\max _{i} x_{i j}^{*}, & \text { for benefit criteria } \\ \min _{i} x_{i j}^{*}, & \text { for cost criteria. }\end{cases}
$$

Step 5 (the full multiplicative form). The preferred alternative is obtained by

$$
A_{M F}^{*}=\left\{A_{i} \mid \max _{i} u_{i}^{*}\right\},
$$

where

$$
u_{i}^{*}=\frac{\prod_{j=1}^{g}\left(x_{i j}^{*}\right)^{w_{j}}}{\prod_{j=g+1}^{n}\left(x_{i j}^{*}\right)^{w_{j}}} .
$$

Step 6 (rank the alternatives). Firstly, the overall evaluations are ranked in descending order, the absolute values are ranked in ascending order, and the overall utility values are ranked in descending order. Then, after the calculation of the subordinate rank results, the above three rankings of alternatives are integrated into a final MULTIMOORA ranking on the basis of the generalized dominance relations of the dominance theory. The dominance theory [52] is a tool for ranking the subordinate alternatives by the MULTIMOORA method, which includes the plurality rule assisted with a kind of lexicographic method and the method of correlation of ranks. 


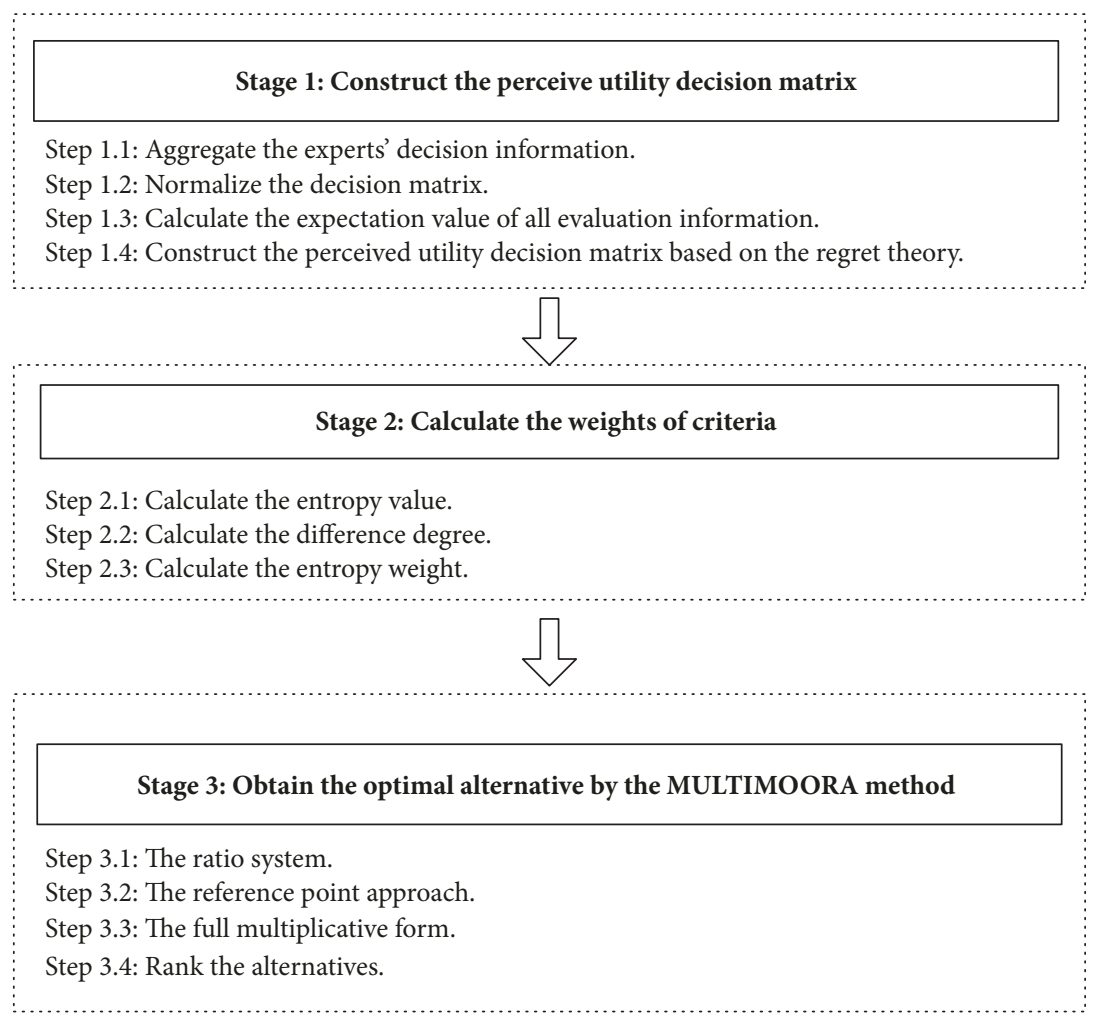

FIGURE 1: The flowchart of the TDUL-RT-MULTIMOORA method.

\section{The TDUL-RT-MULTIMOORA Approach for the PBRMDM Problem}

3.1. Description of the PBRMDM Problem. Suppose $A=$ $\left\{A_{1}, A_{2}, \ldots, A_{m}\right\}$ is a set of the power battery recycling modes, $C=\left\{C_{1}, C_{2}, \ldots, C_{n}\right\}$ is a set of criteria, and $w=$ $\left\{w_{1}, w_{2}, \ldots, w_{n}\right\}$ is the weights of criteria, where $w_{j} \geq 0$ and $\sum_{j=1}^{n} w_{j}=1$. Let $E_{k}(k=1,2, \ldots, t)$ be a set of experts, and $\gamma=\left(\gamma_{1}, \gamma_{2}, \ldots, \gamma_{t}\right)$ is the weights of the experts, where $\gamma_{k} \geq 0$ and $\sum_{k=1}^{t} \gamma_{k}=1$. Expert $E_{k}(k=1,2, \ldots, t)$ gives his/her evaluation $\widehat{s}_{i j}^{(k)}=\left(\left[\dot{s}_{a_{i j}}^{(k)}, \dot{s}_{b_{i j}}^{(k)}\right],\left[\dot{s}_{c_{i j}}^{(k)}, \ddot{s}_{d_{i j}}^{(k)}\right]\right)$ to the mode $A_{i}(i=$ $1,2, \ldots, m)$ with respect to the criteria $C_{j}(j=1,2, \ldots, n)$ by TDULVs, where $\dot{s}_{a_{i j}}^{(k)}, \dot{s}_{b_{i j}}^{(k)} \in S_{\mathrm{I}}, S_{\mathrm{I}}=\left\{\dot{s}_{0}, \dot{s}_{1}, \ldots, \dot{s}_{g-1}\right\}$ and $\ddot{s}_{c_{i j}}^{(k)}, \ddot{s}_{d_{i j}}^{(k)} \in S_{\mathrm{II}}, S_{\mathrm{II}}=\left\{\ddot{s}_{0}, \ddot{s}_{1}, \ldots, \ddot{s}_{h-1}\right\}$. The flowchart of the TDUL-RT-MULTIMOORA method is demonstrated in Figure 1.

3.2. TDUL-RT-MULTIMOORA Method. To solve the PBRMDM problem, an extended MULTIMOORA method with the TDULVs and the regret theory, called the TDUL-RTMULTIMOORA method, is put forward. The decision processes of the TDUL-RT-MULTIMOORA method are described as follows.

Stage 1. Construct the perceived utility decision matrix.
Step 1.1. The evaluations of experts are aggregated by

$$
\begin{aligned}
& \operatorname{TDULDWA}\left(\widehat{s}_{i j}^{(1)}, \widehat{s}_{i j}^{(2)}, \ldots, \widehat{s}_{i j}^{(t)}\right)=\sum_{e=1}^{l} \xi_{e} W A A\left(\widehat{S}_{e}^{(k)}\right) \\
& =\sum_{e=1}^{l} \xi_{e}\left(\sum_{k=1}^{k_{e}} \gamma_{k}^{(e)} \widehat{s}_{i j}^{(k)(e)}\right) \\
& =\left(\left[\dot{S}_{\sum_{e=1}^{l}} \xi_{e} \sum_{k=1}^{k_{e}} \gamma_{k}^{(e)} a_{i j}^{(k)(e)}, \dot{s}_{\left.\sum_{e=1}^{l} \xi_{e} \sum_{k=1}^{k_{e}} \gamma_{k}^{(e)} b_{i j}^{(k)(e)}\right],}\right.\right. \\
& \left.\left[\ddot{s}_{\min c_{i j}^{(k)}} \ddot{s}_{\min d_{i j}^{(k)}}\right]\right),
\end{aligned}
$$

where

$$
\xi_{e}=\frac{\beta_{e}\left(k_{e} / t\right)}{\sum_{e=1}^{l} \beta_{e}\left(k_{e} / t\right)},
$$

where $i=1,2, \ldots, m ; j=1,2, \ldots, n ; e=$ $1,2, \ldots, l\left(\xi_{1}, \xi_{2}, \ldots, \xi_{l}\right)$ is the density weighted vector, $\xi_{e} \in(0,1), \sum_{e=1}^{l} \xi_{e}=1 ; \beta_{e} \geq 0$ is the density influence index and $\beta_{e}=\left(k_{e} / t\right)^{\theta} ; k_{e}$ is the number of the elements in $\widehat{S}_{e}^{(k)}(e=1,2, \ldots, l), \sum_{e=1}^{l} k_{e}=t ; k_{e} / t$ is the scale information of the eth clustered group $\widehat{S}_{e}^{(k)} ; \gamma^{(e)}=\left(\gamma_{1}^{(e)}, \gamma_{2}^{(e)}, \ldots, \gamma_{k_{e}}^{(e)}\right)^{T}$ is the weight vector of $\widehat{S}_{e}^{(k)}=\left(\widehat{s}_{i j}^{(1)(e)}, \widehat{s}_{i j}^{(2)(e)}, \ldots, \widehat{s}_{i j}^{\left(k_{e}\right)(e)}\right)$. 
Step 1.2. Normalize the decision matrix $\widehat{S}=\left[\widehat{s}_{i j}\right]_{m \times n}$ into $\widehat{P}=$ $\left[\widehat{p}_{i j}\right]_{m \times n}$.

The TDULV group evaluation decision matrix $\widehat{S}=$ $\left[\widehat{s}_{i j}\right]_{m \times n}(i=1,2, \ldots, m ; j=1,2, \ldots, n)$ is normalized by

$$
\begin{aligned}
& \widehat{p}_{i j} \\
& = \begin{cases}\left(\left[\dot{s}_{\dot{a}_{i j}}, \dot{s}_{\dot{b}_{i j}}\right],\left[\ddot{s}_{\dot{c}_{i j}}, \ddot{s}_{\dot{d}_{i j}}\right]\right), & \text { for benefit criteria } \\
\left(\left[n e g\left(\dot{s}_{\dot{b}_{i j}}\right), n e g\left(\dot{s}_{\dot{a}_{i j}}\right)\right],\left[\ddot{s}_{\dot{c}_{i j}} \ddot{s}_{\dot{d}_{i j}}\right]\right), & \text { for cost criteria. }\end{cases}
\end{aligned}
$$

Step 1.3. The expectation value of all evaluation information is calculated by

$$
E\left(\widehat{s}_{i j}\right)=\frac{a_{i j}+b_{i j}}{2 \times(g-1)} \times \frac{c_{i j}+d_{i j}}{2 \times(h-1)} .
$$

Step 1.4 (calculate the perceived utility values). According to the regret theory, the perceived utility value $u_{i j}$ is got by

$$
\begin{aligned}
u_{i j}= & v\left(E\left(\widehat{s}_{i j}\right)\right) \\
& +R\left(v\left(E\left(\widehat{s}_{i j}\right)\right)-v\left(E^{*}\left(\widehat{s}_{j}\right)\right)\right), \sqrt{b^{2}-4 a c}
\end{aligned}
$$

where

$$
\begin{aligned}
& v\left(E^{*}\left(\widehat{s}_{j}\right)\right)=\max \left\{v\left(E\left(\widehat{s}_{j}\right)\right) \mid j=1,2, \ldots, n\right\}, \\
& v\left(E\left(\widehat{s}_{i j}\right)\right)=\left(E\left(\widehat{s}_{i j}\right)\right)^{\alpha}, \\
& R\left(v\left(E\left(\widehat{s}_{i j}\right)\right)-v\left(E^{*}\left(\widehat{s}_{j}\right)\right)\right) \\
& \quad=1-\exp \left(-\delta\left(v\left(E\left(\widehat{s}_{i j}\right)\right)-v\left(E^{*}\left(\widehat{s}_{j}\right)\right)\right)\right) .
\end{aligned}
$$

Thus, the perceived utility decision matrix $\widehat{U}=\left[u_{i j}\right]_{m \times n}(i=$ $1,2, \ldots, m ; j=1,2, \ldots, n)$ is established.

Stage 2 (calculate the weights of criteria). The entropy weighting method was produced by Shannon [20]. It is a method that employs probability theory to measure the uncertainty of information, which can avoid the negative effect of subjective elements. The entropy weighting method is a useful method to measure the uncertainty in the decision-making problem [53]. The steps of the entropy weighting method are as follows.

Step 2.1. Calculate the entropy value by

$$
\begin{aligned}
E n_{j}=-\frac{1}{\ln m} \sum_{i=1}^{m} u_{i j} \ln u_{i j} & \\
& (i=1,2, \ldots, m ; j=1,2, \ldots, n) .
\end{aligned}
$$

Step 2.2. Calculate the difference degree by

$$
G_{j}=1-E n_{j} \quad(j=1,2, \ldots, n) .
$$

Step 2.3. Calculate the entropy weight of each criterion by

$$
w_{j}=\frac{G_{j}}{\sum_{j=1}^{n} G_{j}} \quad(j=1,2, \ldots, n) .
$$

Stage 3. Rank the recycling modes by the MULTIMOORA method.

Step 3.1 (the ratio system). In order to obtain the optimization, the best recycling mode is determined by

$$
A_{R S}^{*}=\left\{A_{i} \mid \max _{i} y_{i}^{*}\right\}
$$

where

$$
y_{i}^{*}=\sum_{j=1}^{n} w_{j} u_{i j}
$$

Step 3.2 (the reference point approach). The best recycling mode is determined by

$$
A_{R P}^{*}=\left\{A_{i} \mid \min _{i} z_{i}^{*}\right\}
$$

where

$$
\begin{aligned}
z_{i}^{*} & =\max _{j}\left|w_{j} r_{j}-w_{j} u_{i j}\right| \\
r_{j} & =\max _{i} u_{i j} .
\end{aligned}
$$

Step 3.3 (the full multiplicative form). The preference recycling mode is got by

$$
A_{M F}^{*}=\left\{A_{i} \mid \max _{i} \bar{u}_{i}^{*}\right\},
$$

where

$$
\bar{u}_{i}^{*}=\prod_{j=1}^{n}\left(u_{i j}\right)^{w_{j}} .
$$

Step 3.4 (rank the recycling modes). Firstly, the overall evaluation values are ranked in descending order, the absolute values are ranked in ascending order, and the overall utility values are ranked in descending order. Then, after the calculation of the subordinate rank results, a final MULTIMOORA ranking of recycling modes is got based on the dominance theory, and the mode ranking in the first place is the optimal one.

\section{Illustrative Example}

Enterprise B is an electric automobile manufacture company in China. This enterprise began to sell electric vehicles to the market in 2011. By the end of 2017, the total number of electric 
TABLE 1: The recycling modes and criteria for the PBRMDM problem.

\begin{tabular}{lc}
\hline Recycling modes & Criteria \\
\hline & The ability to control the supply chain $\left(C_{1}\right)$ \\
The independent recycling mode $\left(A_{1}\right)$ & Recovery facilities $\left(C_{2}\right)$ \\
The alliance recycling mode $\left(A_{2}\right)$ & Professional construction of recycling $\left(C_{3}\right)$ \\
The third-party recycling mode $\left(A_{3}\right)$ & Recycling scale $\left(C_{4}\right)$ \\
& Recycling cost $\left(C_{5}\right)$ \\
& The situation of recycling resources $\left(C_{6}\right)$ \\
\hline
\end{tabular}

vehicles sold by enterprise B had exceeded 290,000. According to the "national application of new energy automobile production enterprises and product record management rules" of China, the service life of the power battery is 58 years, which means the power batteries sold in the early stage by enterprise B start to enter the scraping period. Therefore, it is necessary for enterprise B to choose the optimal power battery recycling mode in order to save the cost and make a long-term and sustainable development. There are three power battery recycling modes $A=\left\{A_{1}, A_{2}, A_{3}\right\}$ for enterprise $\mathrm{B}$ to choose from, and six criteria $C=$ $\left\{C_{1}, C_{2}, C_{3}, C_{4}, C_{5}, C_{6}\right\}$ are considered (as shown in Table 1). Among the six criteria, it can be seen that $C_{1}, C_{2}, C_{3}$, and $C_{6}$ belong to the benefit criteria, and $C_{4}, C_{5}$ are the cost criteria. Five experts $E=\left\{E_{1}, E_{2}, E_{3}, E_{4}, E_{5}\right\}$ are invited to give their TDULV evaluations to the three recycling modes with respect to the six criteria. Suppose the weights of five experts are the same; that is, $\gamma=\left(\gamma_{1}, \gamma_{2}, \gamma_{3}, \gamma_{4}, \gamma_{5}\right)=$ $(0.2,0.2,0.2,0.2,0.2)$. Then, five TDULV evaluation decision matrices $\widehat{S}^{(k)}=\left[\widehat{s}_{i j}^{(k)}\right]_{3 \times 6}(k=1,2,3,4,5)$ are obtained. The target of PBRMDM is to determine the optimal recycling mode. Due to the limitation of space, here we only give the TDULV evaluation decision matrix given by the first expert $E_{1}$, which is shown in Table 2 .

\subsection{The Decision Process and Results}

Stage 1. Construct the perceived utility decision matrix.

Step 1.1. Let $\theta=0$, and, based on the TDULDWA operator, the TDULV decision matrices $\widehat{S}^{(k)}=\left[\widehat{s}_{i j}^{(k)}\right]_{3 \times 6}(k=1,2,3,4,5)$ by the five experts are aggregated into a group linguistic decision matrix $\widehat{S}=\left[\widehat{s}_{i j}\right]_{3 \times 6}$ by (21)-(22) as shown in Table 3 .

Step 1.2. The normalized linguistic decision matrix $\widehat{P}=$ $\left[\widehat{p}_{i j}\right]_{3 \times 6}$ is obtained by (23), which is presented in Table 4.

Step 1.3. The normalized linguistic decision matrix $\widehat{P}=$ $\left[\widehat{p}_{i j}\right]_{3 \times 6}$ is transformed into a crisp decision matrix $\widehat{S}=\left[\widehat{s}_{i j}\right]_{3 \times 6}$ according to (24) as listed in Table 5.

Step 1.4. The perceived utility decision matrix $\widehat{U}=\left[u_{i j}\right]_{3 \times 6}$ is obtained by calculating the perceived utility value $u_{i j}$ according to (25)-(28), and the results are shown in Table 6.

Stage 2. Calculate the weights of criteria by the entropy weighting method.
Step 2.1. The entropy values of criteria are calculated by (29), and the results are $E n_{1}=0.902, E n_{2}=0.930, E n_{3}=0.926$, $E n_{4}=0.934, E n_{5}=0.940$, and $E n_{6}=0.958$.

Step 2.2. The different degrees of criteria are obtained by (30), and the calculating results are $G_{1}=0.098, G_{2}=0.070, G_{3}=$ $0.074, G_{4}=0.066, G_{5}=0.060$, and $G_{6}=0.042$.

Step 2.3. By (31), the weights of criteria are calculated as $w_{1}=$ $0.239, w_{2}=0.171, w_{3}=0.180, w_{4}=0.160, w_{5}=0.147$, and $w_{6}=0.103$.

Stage 3. Rank the recycling modes by the MULTIMOORA method.

Step 3.1 (the ratio system). First, the overall evaluation value $y_{i}^{*}$ of the recycling mode $A_{i}$ refers to each criterion which is calculated according to (33), and the results are $y_{1}^{*}=0.349$, $y_{2}^{*}=0.377$, and $y_{3}^{*}=0.391$. Then, based on the ratio system and by (32), the ranking of three recycling modes is $A_{3}>$ $A_{2}>A_{1}$.

Step 3.2 (the reference point approach). First, the absolute value between the reference point $r_{j}$ and the normalized evaluation value of the recycling mode $A_{i}$ refers to criteria $C_{j}$ calculated according to (35)-(36), and the results are $z_{1}^{*}=$ $0.060, z_{2}^{*}=0.057$, and $z_{3}^{*}=0.098$. Then, based on the reference point approach and by (34), the ranking of three recycling modes is $A_{2}>A_{1}>A_{3}$.

Step 3.3 (the full multiplicative form). First, the overall utility of the recycling mode $A_{i}$ is calculated according to (38), and the results are $\bar{u}_{1}^{*}=0.322, \bar{u}_{2}^{*}=0.366$, and $\bar{u}_{3}^{*}=0.348$. Then, based on the full multiplicative form and by (37), the ranking of three recycling modes is $A_{2}>A_{3}>A_{1}$.

Step 3.4 (rank the recycling modes). According to the ranking results obtained by Steps 3.1, 3.2, and 3.3, combining with the dominance theory, the final ranking of three recycling modes is $A_{2}>A_{3}>A_{1}$. As a result, $A_{2}$ is the optimal recycling modes.

4.2. Comparative Analysis. In this section, a comparative analysis is conducted to demonstrate the effectiveness and advantages of the proposed TDUL-RT-MULTIMOORA method. The result of the proposed method is compared with the result of the VIKOR method [28] and the TODIM method [54], and the ranking results of the three methods are listed in Table 7. 


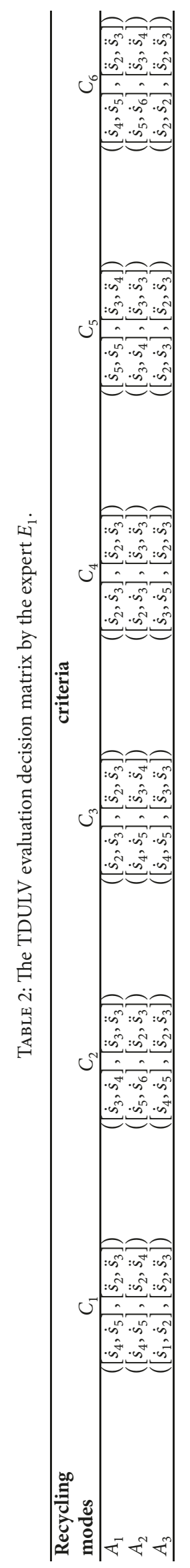




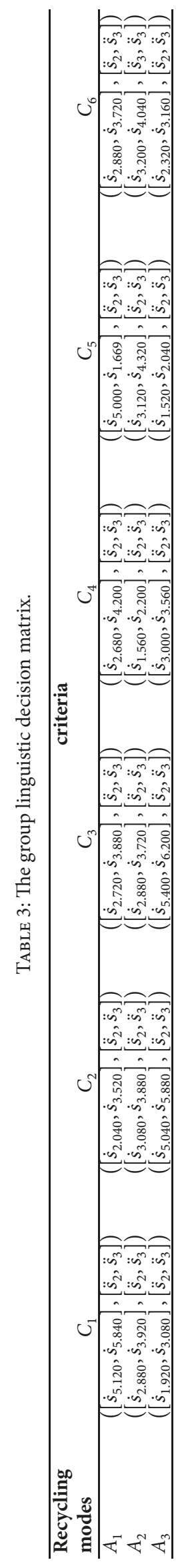




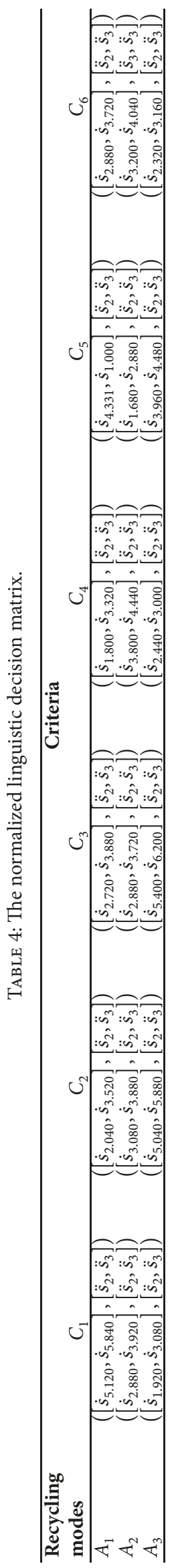


TABLE 5: The crisp decision matrix.

\begin{tabular}{lcccccc}
\hline $\begin{array}{l}\text { Recycling } \\
\text { modes }\end{array}$ & $C_{1}$ & $C_{2}$ & $C_{3}$ & $C_{4}$ & $C_{5}$ & 0.278 \\
\hline$A_{1}$ & 0.571 & 0.290 & 0.344 & 0.267 & 0.244 \\
$A_{2}$ & 0.354 & 0.363 & 0.344 & 0.429 & 0.238 \\
$A_{3}$ & 0.260 & 0.569 & 0.604 & 0.283 & 0.440 & 0.285 \\
\hline
\end{tabular}

TABLE 6: The perceived utility decision matrix.

\begin{tabular}{lcccccc}
\hline $\begin{array}{l}\text { Recycling } \\
\text { modes }\end{array}$ & $C_{1}$ & $C_{2}$ & $C_{3}$ & $C_{4}$ & $C_{5}$ & 0.323 \\
\hline$A_{1}$ & 0.611 & 0.250 & 0.323 & 0.219 & 0.234 & 0.498 \\
$A_{2}$ & 0.372 & 0.383 & 0.358 & 0.468 & 0.215 & 0.437 \\
$A_{3}$ & 0.200 & 0.599 & 0.642 & 0.231 & 0.234 \\
\hline
\end{tabular}

TABLE 7: Ranking results using different methods.

\begin{tabular}{lc}
\hline Method & $\begin{array}{c}\text { Ranking of the recycling } \\
\text { modes }\end{array}$ \\
\hline The TDUL-RT-MULTIMOORA method & $A_{2}>A_{3}>A_{1}$ \\
The VIKOR method & $A_{2}>A_{1}>A_{3}$ \\
The TODIM method & $A_{2}>A_{1}>A_{3}$ \\
\hline
\end{tabular}

From Table 7, it can be seen that the optimal power battery recycling modes gained by the three methods are the same, which illustrate the effectiveness of the proposed method, while the second and the third place of the ranking obtained by the proposed method are slightly different from the other two methods. The main reasons for the differences are as follows: firstly, the TDUL-RT-MULTIMOORA method not only considers the outcome of the recycling mode choice but also pays attention to the possible result of the unselected recycling modes. Secondly, in the process of decision-making, the VIKOR method and the TODIM method focus on considering the limited rationality of the decision makers, without taking the robustness of the decision-making system into consideration. In the MULTIMOORA method, a robust system is constructed in the entire process of decision-making, which helps to enhance the accuracy and stability of the decision-making result. Thirdly, in the reality, the recycling of the power batteries involves multiple organizations, professional knowledge, and special equipment. The competitive strategy made by enterprise B involves the innovation and manufacturing of the electric vehicles. Compared with the independent recycling mode, the third-party recycling mode can not only help enterprise $B$ reduce the recycling cost but also improve the efficiency and quality of recycling.

Compared with the VIKOR and TODIM method, the advantages of the proposed method are listed as follows:

(1) In this paper, the evaluations to alternatives over criteria given by decision makers are presented by the TDULVs. The TDULVs can not only represent the assessments of experts but also consider the reliability of the experts' subject evaluations, which can express the fuzziness or uncertainty information well and keep the integrity of the primary information.

(2) The entropy weighting method avoids the disadvantages of subjective weight method, such as completely deviating from the measured data and heavily depending on the experience and knowledge of the experts, and it is an important measure of uncertainty by fully using the data.

(3) The VIKOR method and the TODIM method only consider the limited rationality of the decision makers, while the proposed method not only considers the decision makers' limited rationality but also takes the possible regret psychological behaviour that the decision makers may produce in the process of decisionmaking into account, which is more in line with the reality.

(4) The regret theory applied in the proposed method is an important behaviour decision-making theory by considering both the outcomes of the alternative choices and the possible results of unselected alternatives, which is easier and more consistent to depict intuitive judgments of decision makers.

(5) The proposed method takes the robustness of the decision-making system into consideration by extending the MULTIMOORA method.

In short, the proposed method not only improves the accuracy of the evaluations by decision makers but also takes the decision makers' psychological behaviour and the robustness of decision system into account; thus, the proposed method in this paper is more comprehensive and precise than the VIKOR and TODIM method.

\section{Conclusions}

In order to solve the PBRMDM problem, a TDUL-RTMULTIMOORA method combining with the regret theory 
and the MULTIMOORA method based on the TDULVs is proposed. The TDUL-RT-MULTIMOORA method not only can improve the accuracy of the evaluations by decision makers but also takes the robustness of decision system into account, which helps to ensure the stability of the result. Firstly, the assessments of decision makers are expressed by the TDULVs, and the assessments of decision makers are aggregated into a group linguistic decision matrix by the TDULDWA operator. On this basis, the regret theory is introduced to describe the limited rationality of the decision makers, including taking both the outcomes of the power battery recycle mode choice and the possible result of unselected power battery recycle modes into consideration. Secondly, the weights of criteria are obtained by the entropy weighting method. Furthermore, the MULTIMOORA method is applied to rank the power battery recycle modes. Finally, an example is given to illustrate the efficiency and the practicability of the proposed method.

The novelty aspects of the proposed method are listed as follows:

(1) The TDULVs used to represent the assessments of experts considers the reliability of the experts' subject evaluations, which is better for expressing the fuzziness and uncertainty of assessment information. Therefore, the proposed approach can be able to represent the evaluations of decision makers more precisely and practically. In addition, the TDULDWA operator can make sure effective aggregation of evaluation information is given by experts.

(2) The weights of criteria are calculated by the entropy weighting method, which can fully use the original information and avoid the deviation from the measured data, which makes the result more precise.

(3) An extended MULTIMOORA method combined with the TDULVs and regret theory is proposed for solving the PBRMDM problem. The proposed method can not only improve the accuracy of evaluations by decision makers but also consider the robustness of decision system, and it ensures the stability of the result. The proposed method provides a new method to solve this problem in a more precise way.

In terms of future research, it is required that the proposed method can be extended to support PBRMDM problems by considering more complex influencing factors. In addition, we will try to investigate more linguistic computing techniques to improve the reliability and accuracy of representing the decision makers' evaluation information.

\section{Data Availability}

The data used to support the findings of this study are available from the corresponding author upon request.

\section{Conflicts of Interest}

The authors declare that there are no conflicts of interest regarding the publication of this paper.

\section{Acknowledgments}

This research was funded by the National Natural Science Foundation of China (no. 71502098), the Humanities and Social Sciences projects of the Ministry of Education (no. 13YJC630023), and the Horizontal Project of Shanghai University.

\section{References}

[1] W. Bulach, D. Schüler, G. Sellin et al., "Electric vehicle recycling 2020: key component power electronics," Waste Management \& Research, vol. 36, no. 4, p. 311, 2018.

[2] J. Ordoñez, E. J. Gago, and A. Girard, "Processes and technologies for the recycling and recovery of spent lithium-ion batteries," Renewable \& Sustainable Energy Reviews, vol. 60, pp. 195-205, 2016.

[3] Y. Wu, C. Xie, C. Xu, and F. Li, "A decision framework for electric vehicle charging station site selection for residential communities under an intuitionistic fuzzy environment: a case of beijing," Energies, vol. 10, no. 9, 2017.

[4] M. R. Fisher, C. W. Churchman, R. L. Ackoff, and E. L. Arnoff, "Introduction to operations research," The Economic Journal, vol. 69, no. 276, p. 785, 1959.

[5] M. M. Wiecek, M. Ehrgott, G. Fadel, and J. R. Figueira, "Multiple criteria decision making for engineering," Omega, vol. 36, no. 3, pp. 337-339, 2008.

[6] L. Yun, D. Linh, and L. Shui, "Metallurgical and mechanical methods for recycling of lithium-ion battery pack for electric vehicles," Resources Conservation \& Recycling, vol. 136, pp. 198208, 2018.

[7] W. Liu and H. Gao, "The urgency and countermeasures of power lithium battery recycling in China," Industrial Economy Review, 2017.

[8] Y. Tang, Q. Zhang, Y. Li, G. Wang, and Y. Li, "Recycling mechanisms and policy suggestions for spent electric vehicles' power battery-a case of Beijing," Journal of Cleaner Production, vol. 186, pp. 388-406, 2018.

[9] Z. Xu, "Induced uncertain linguistic OWA operators applied to group decision making," Information Fusion, vol. 7, no. 2, pp. 231-238, 2006.

[10] P. Liu and F. Teng, "An extended TODIM method for multiple attribute group decision-making based on 2-dimension uncertain linguistic Variable," Complexity, vol. 21, no. 5, pp. 20-30, 2014.

[11] P. Liu, "An approach to group decision making based on 2dimension uncertain linguistic information," Technological and Economic Development of Economy, vol. 18, no. 3, pp. 424-437, 2012.

[12] P. D. Liu, L. He, and X. C. Yu, "Generalized hybrid aggregation operators based on the 2-dimension uncertain linguistic information for multiple attribute group decision making," Group Decision and Negotiation, vol. 25, no. 1, pp. 103-126, 2016.

[13] W. Liu, H. Liu, and L. Li, "A Multiple attribute group decision making method based on 2-D uncertain linguistic weighted heronian mean aggregation operator," International Journal of Computers, Communications \& Control, vol. 12, no. 2, pp. 254264,2017

[14] K. Yin, B. Yang, and X. Li, "Multiple attribute group decisionmaking methods based on trapezoidal fuzzy two-dimensional linguistic partitioned bonferroni mean aggregation operators," 
International Journal of Environmental Research \& Public Health, vol. 15, no. 2, p. 194, 2018.

[15] G. Loomes and R. Sugden, "Regret theory: an alternative theory of rational choice under uncertainty," The Economic Journal, vol. 92, no. 368, pp. 805-824, 1982.

[16] Y. Wang, "Regret-based automated decision-making AIDS for domain search tasks using human-agent collaborative teams," IEEE Transactions on Control Systems Technology, vol. 24, no. 5, pp. 1680-1695, 2016.

[17] M. Li and H.-J. Huang, "A regret theory-based combined trip distribution and traffic assignment model," in Proceedings of the 16th COTA International Conference of Transportation Professionals: Green and Multimodal Transportation and Logistics, CICTP 2016, pp. 2116-2127, July 2016.

[18] W. Song, Z. Chen, X. Wang, Q. Wang, C. Shi, and W. Zhao, "Environmentally friendly supplier selection using prospect theory," Sustainability, vol. 9, no. 3, p. 377, 2017.

[19] Y. Yang and J. Wang, "SMAA-based model for decision aiding using regret theory in discrete Z-number context," Applied Soft Computing, vol. 65, pp. 590-602, 2018.

[20] C. E. Shannon, "A mathematical theory of communication," Bell Labs Technical Journal, vol. 27, pp. 379-423, 1948.

[21] S. T. Wan, X. Zhang, and L. J. Dong, "Shannon entropy of binary wavelet packet subbands and its application in bearing fault extraction," Entropy, vol. 20, no. 4, p. 260, 2018.

[22] D. Liu and L. Li, "Application study of comprehensive forecasting model based on entropy weighting method on trend of PM2.5 concentration in Guangzhou, China," International Journal of Environmental Research and Public Health, vol. 12, no. 6, pp. 7085-7099, 2015.

[23] A. Delgado and E. C. Reyes, "Applying shannon entropy to select alternative plants as food for livestock: a case study in Ecuador," in Proceedings of the 2016 IEEE Congreso Argentino de Ciencias de la Informática y Desarrollos de Investigación (CACIDI), pp. 1-5, Buenos Aires, Argentina, November 2016.

[24] C. Zhang, H. Zhang, C. Wang et al., "A novel ship detection method based on Chinese Gaofen-3 fully polarimetric SAR images," IEEE Progress in Electromagnetics Research Symposium, pp. 909-916, 2017.

[25] W. K. M. Brauers and E. K. Zavadskas, "The MOORA method and its application to privatization in a transition economy," Control and Cybernetics, vol. 25, no. 2, pp. 445-469, 2006.

[26] T. L. Saaty, The Analytic Hierarchy Process, McGraw-Hill, New York, NY, USA, 1980.

[27] C. L. Hwang and K. Yoon, Multiple Attribute Decision Making: Methods and Applications, vol. 186 of Lecture Notes in Economics and Mathematical Systems, Springer, Heidelberg, Germany, 1981.

[28] S. Opricovic, Multi-Criteria Optimization of Civil Engineering Systems, Faculty of Civil Engineering, Belgrade, Serbia, 1998.

[29] B. Roy, R. Benayoun, and B. Sussman, ELECTRE, Société d'economie et de mathématique appliquées, 1966.

[30] B. Mareschal, J. P. Brans, and P. Vincke, Prométhée: A New Family of Outranking Methods in Multicriteria Analysis, Ulb Institutional Repository, 1984.

[31] S. Chakraborty, "Applications of the MOORA method for decision making in manufacturing environment," The International Journal of Advanced Manufacturing Technology, vol. 54, no. 9, pp. 1155-1166, 2011.

[32] W. K. M. Brauers and E. K. Zavadskas, "Project management by multimoora as an instrument for transition economies,"
Technological and Economic Development of Economy, vol. 16, no. 1, pp. 5-24, 2010.

[33] W. K. Brauers and E. K. Zavadskas, "Robustness of MULTIMOORA: a method for multi-objective optimization," Informatica, vol. 23, no. 1, pp. 1-25, 2012.

[34] A. Hafezalkotob, A. Hafezalkotob, and M. K. Sayadi, "Extension of MULTIMOORA method with interval numbers: an application in materials selection," Applied Mathematical Modelling, vol. 40, no. 2, pp. 1372-1386, 2016.

[35] A. Hafezalkotob and A. Hafezalkotob, "Interval MULTIMOORA method with target values of attributes based on interval distance and preference degree: biomaterials selection," Journal of Industrial Engineering International, vol. 13, no. 2, pp. 181-198, 2017.

[36] M. Eghbali-Zarch, R. Tavakkoli-Moghaddam, F. Esfahanian, M. Sepehri, and A. Azaron, "Pharmacological therapy selection of type 2 diabetes based on the SWARA and modified MULTIMOORA methods under a fuzzy environment," Artificial Intelligence in Medicine, vol. 87, pp. 20-33, 2018.

[37] L. Gigović, D. Pamuĉar, Z. Bajić, and M. Milićević, “The combination of expert judgment and GIS-MAIRCA analysis for the selection of sites for ammunition depots," Sustainability, vol. 8, no. 4, 2016.

[38] Ž. Stević, D. Pamučar, M. Vasiljević, G. Stojić, and S. Korica, "Novel integrated multi-criteria model for supplier selection: case study construction company," Symmetry, vol. 9, no. 11, 2017.

[39] R. Fattahi and M. Khalilzadeh, "Risk evaluation using a novel hybrid method based on FMEA, extended MULTIMOORA, and AHP methods under fuzzy environment," Safety Science, vol. 102, pp. 290-300, 2018.

[40] R. R. Yager, “Generalized OWA aggregation operators," Fuzzy Optimization and Decision Making, vol. 3, no. 1, pp. 93-107, 2004.

[41] P. Liu and X. Yu, 2-Dimension Uncertain Linguistic Power Generalized Weighted Aggregation Operator and Its Application in Multiple Attribute Group Decision Making, Elsevier Science Publishers, 2014.

[42] J. Q. Wang and J. J. Li, “The multi-criteria group decision making method based on multi-granularity intuitionistic two semantics," Science \& Technology Information, vol. 33, pp. 8-9, 2009.

[43] W. D. Zhu, G. Z. Zhou, and S. L. Yang, "An approach to group decision making based on 2-dimension linguistic assessment information," Systems Engineering, vol. 27, no. 2, pp. 113-118, 2009.

[44] J. C. Harsanyi, "Cardinal welfare, individualistic ethics, and interpersonal comparisons of utility," Journal of Political Economy, vol. 63, no. 4, pp. 309-321, 1955.

[45] P. Liu and F. Teng, "Multiple attribute decision-making method based on 2-dimension uncertain linguistic density generalized hybrid weighted averaging operator," Soft Computing, pp. 1-14, 2016.

[46] P. Yi, Y. Guo, and D. Zhang, "Density weighted averaging middle operator and application in multi-attribute decision making," Control \& Decision, vol. 22, no. 5, pp. 515-398, 2007.

[47] D. E. Bell, "egret in decision making under uncertainty," Operations Research, vol. 30, pp. 961-981, 1982.

[48] C. G. Chorus, "Regret theory-based route choices and traffic equilibria," Transportmetrica, vol. 8, no. 4, pp. 291-305, 2012.

[49] J. Quiggin, "Regret theory with general choice sets," Journal of Risk and Uncertainty, vol. 8, no. 2, pp. 153-165, 1994. 
[50] A. Tversky and D. Kahneman, "Advances in prospect theory: cumulative representation of uncertainty," Journal of Risk and Uncertainty, vol. 5, no. 4, pp. 297-323, 1992.

[51] C. E. Laciana and E. U. Weber, "Correcting expected utility for comparisons between alternative outcomes: a unified parameterization of regret and disappointment," Journal of Risk and Uncertainty, vol. 36, no. 1, pp. 1-17, 2008.

[52] W. K. M. Brauers and E. K. Zavadskas, "Multimoora optimization used to decide on a bank loan to buy property," Technological and Economic Development of Economy, vol. 17, no. 1, pp. 174-188, 2011.

[53] J. Yang, Y. Feng, and W. Qiu, "Stock selection for portfolios using expected utility-entropy decision model," Entropy, vol. 19, no. 10, 2017.

[54] L. F. A. M. Gomes and M. M. P. P. Lima, "Todim: basic and application to multicriteria ranking of projects with environmental impacts," Paris, vol. 16, pp. 113-127, 1991. 


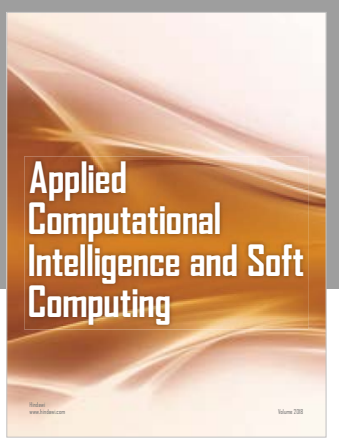

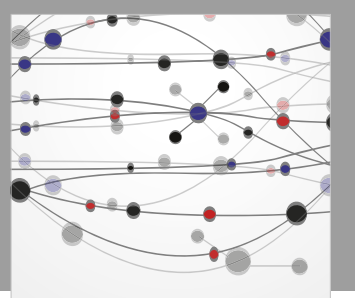

The Scientific World Journal
Submit your manuscripts at

Computing
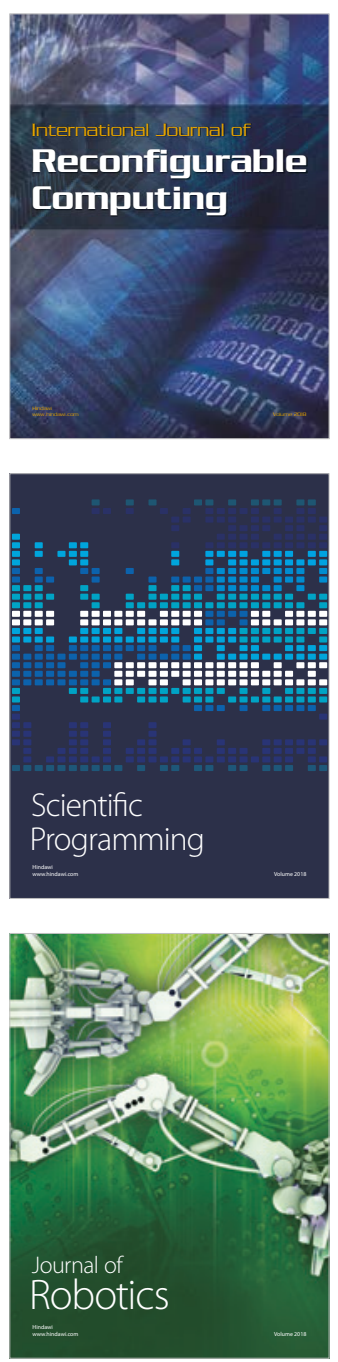

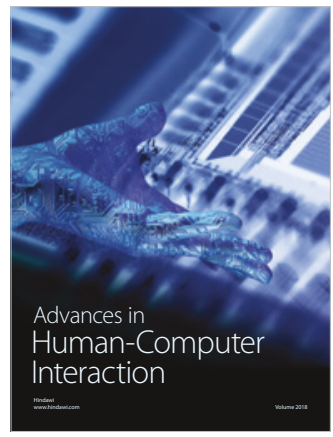

Human-Compute

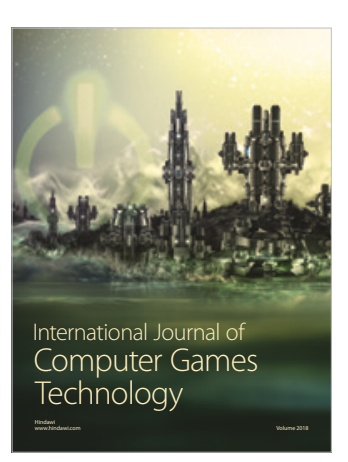

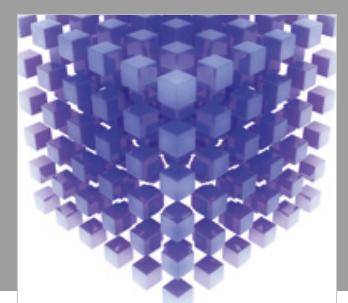

Mathematical Problems in Engineering

\section{Engincering}
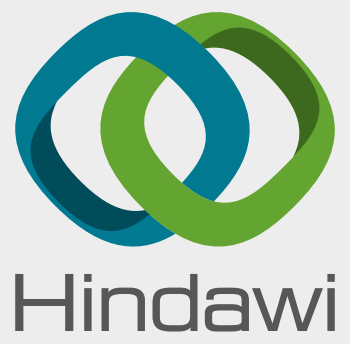

www.hindawi.com
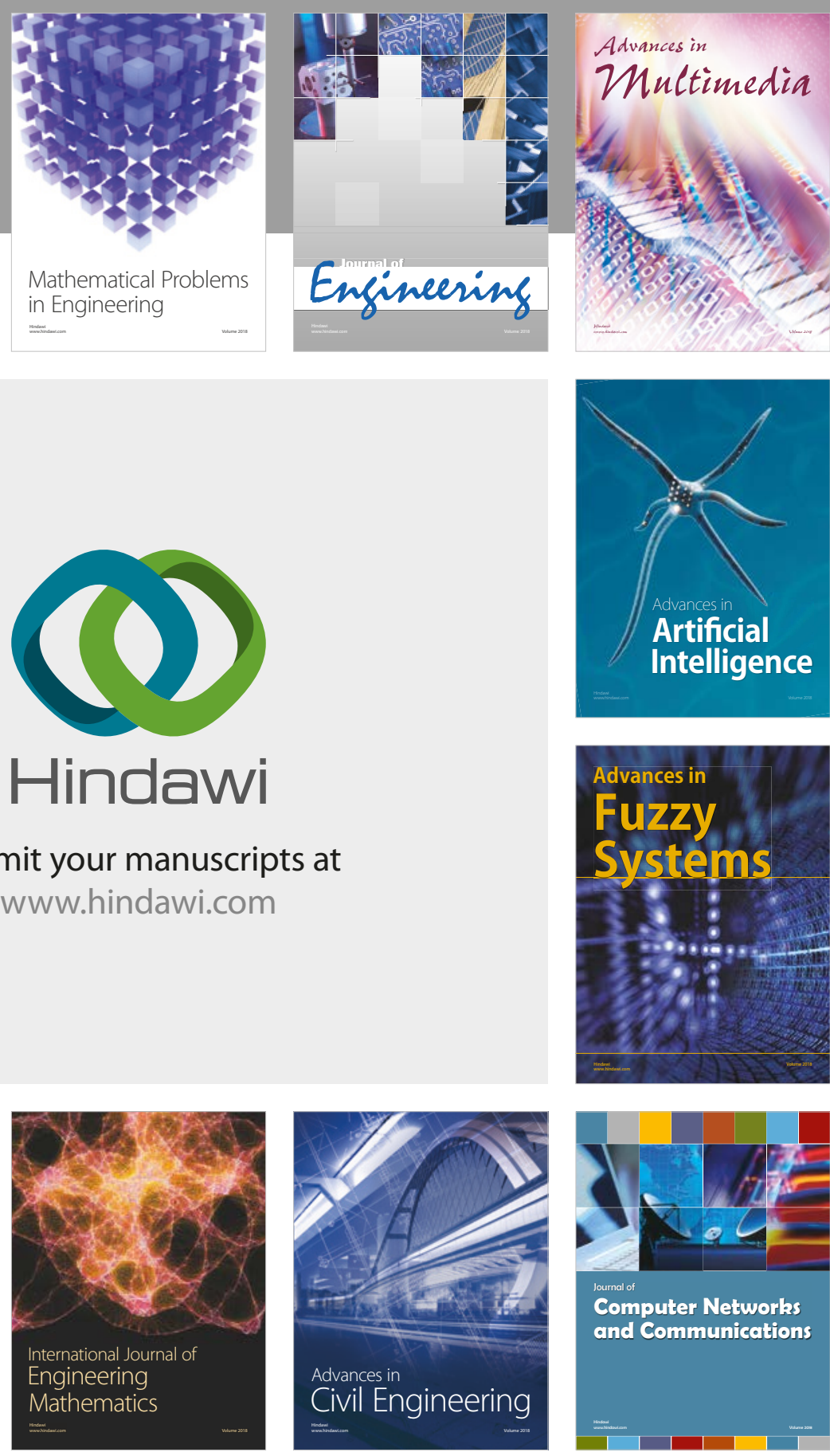

Computer Networks and Communications

Multimedia
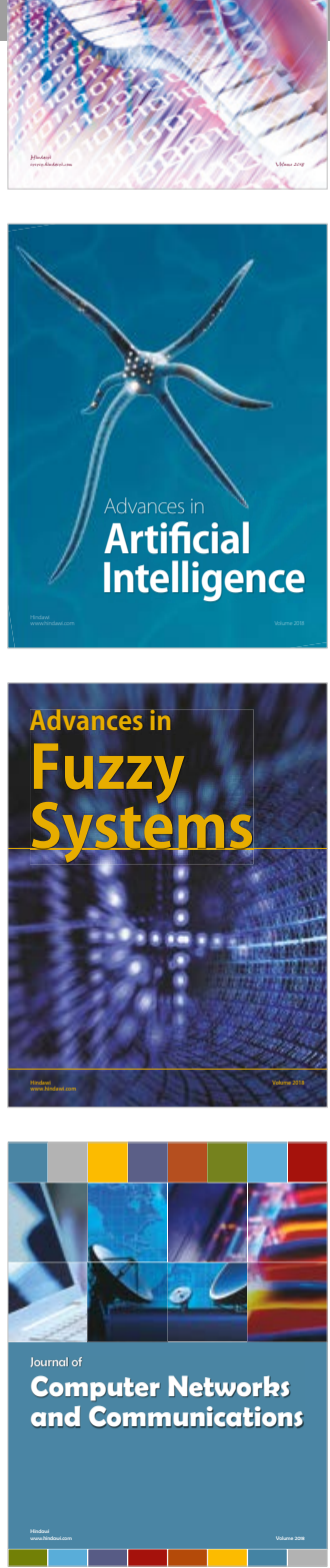

Advances in

Modelling \&

Simulation

in Engineering

interaction

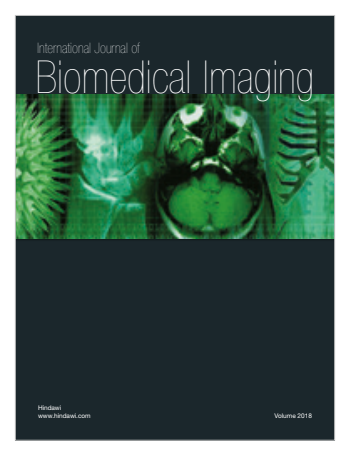

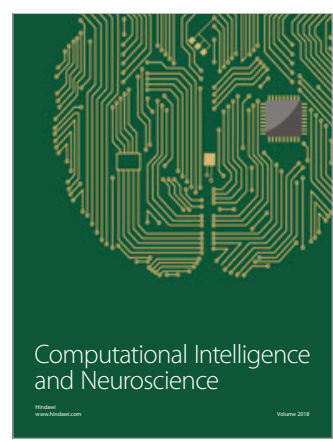

